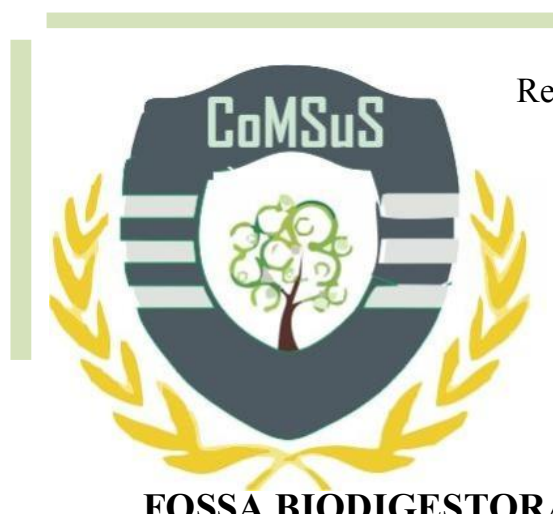

Recebido em 24/05/2018. Aprovado em 12/06/2018. Publicado em 08/11/2018.

Editor: Dr. Ivano Ribeiro

Processo de Avaliação: Double Blind Review - SEER/OJS

e-ISSN: 2359-5876

https://doi.org/10.5935/2359-5876.20180005

\title{
FOSSA BIODIGESTORA: LIÇÕES APRENDIDAS NA INSTALAÇÃO DE DOIS PROJETOS EM ZONAS RURAIS
}

\section{BIODIGESTORA FOSSA: LESSONS LEARNED IN THE INSTALLATION OF TWO PROJECTS IN RURAL AREAS}

\author{
Bruna Brandini Carrilho ${ }^{1}$ \\ Wilson Levy Braga da Silva Neto ${ }^{2}$ \\ David Timóteo Carrilho Leite ${ }^{3}$ \\ Fábio Ytoshi Shibao ${ }^{4}$
}

\section{RESUMO}

No mundo, cerca de 2,6 bilhões de pessoas não utilizam nenhum tipo de sistema de fossa séptica e não são atendidas pelo sistema de rede coletora de esgoto da rede pública. No Brasil metade da população não possui acesso à rede pública de coleta de esgoto e 35 milhões de pessoas não possuem banheiros em suas residências. Estima-se que aproximadamente 1,7 bilhões de casos de doenças recorrentes da diarreia e cerca de $90 \%$ das mortes causadas pela doença são decorrentes da falta de tratamento de esgoto. Para solucionar este problema nos últimos anos surgiram diversas técnicas de saneamento residencial e rural, que visam tratar o esgoto em pequena escala e com menor tempo, entre elas a fossa séptica e a fossa séptica biodigestora. Considerando este contexto, por meio de uma pesquisa-ação, o presente relato visa apresentar o modelo de fossa biodigestora, os principais pontos de atenção da instalação deste tipo de fossa em zonas rurais, por meio de dois projetos executados na cidade de Pedro de Toledo-SP.

Palavras-chave: Fossa; Esgoto; Rural; Tratamento de esgoto; Fossa séptica.

\begin{abstract}
In the world, about 2.6 billion people do not use any type of septic system and are not served by the public sewage system. In Brazil half the population does not have access to the public sewage collection network and 35 million people do not have toilets in their homes. It is estimated that approximately 1.7 billion cases of recurrent diarrheal diseases and about $90 \%$ of the deaths caused by the disease are due to the lack of sewage treatment. In order to solve this problem in recent years, several techniques of residential and rural sanitation have emerged, which aim to treat small-scale, time-limited sewage treatment, including septic tank and biodigester septic tank. Considering this context, through an action research, the present report aims to present the biodigestose fossa model, the main attention points of the installation of this type of pit in rural areas, through two projects executed in the city of Pedro de Toledo -SP.
\end{abstract}

Keywords: Fossa; Sewage; Rural; Sewage treatment; Septic tank.

${ }^{1}$ Mestrado em andamento em Cidades Inteligentes e Sustentáveis pela Universidade Nove de Julho - Uninove. Email: brunabrandini_ambiente@hotmail.com

${ }^{2}$ Doutor em Direito pela Pontifícia Universidade Católica de São Paulo. Professor do Programa de Pós-graduação em Cidades Inteligentes e Sustentáveis da Universidade Nove de Julho - Uninove. E-mail: wilsonlevy@gmail.com

${ }^{3}$ Especialista em processos de negócio com ênfase em SOA pela Faculdade de Informática e Administração Paulista. Filiação: Universidade Nove de Julho - Uninove. E-mail: dvcarrilho@gmail.com

${ }^{4}$ Doutor em Administração de Empresas pela Universidade Presbiteriana Mackenzie. Professor Pesquisador do Programa de Mestrado Profissional em Administração; Gestão Ambiental e Sustentabilidade; e Mestrado em Cidades Inteligentes e Sustentáveis da Universidade Nove de Julho - Uninove. E-mail: fabio.shibao@gmail.com 


\section{INTRODUÇÃO}

Segundo relatório divulgado em 2010 pela Organização Mundial de Saúde (OMS) e pelo Fundo das Nações Unidas para a Infância (UNICEF), cerca de 2,6 bilhões de pessoas não utilizam nenhum tipo de sistema de fossa séptica e não são atendidas pelo sistema de rede coletora de esgoto da rede pública.

Trazendo esse contexto para a realidade brasileira, pode-se ressaltar que apesar do país possuir $12 \%$ de toda a água doce do planeta, 22 milhões de pessoas não possuem acesso à água de boa qualidade, em função da falta de tratamento correto de efluentes, pois grande parte desta água é contaminada por esgoto e outros resíduos (Embrapa, 2010).

Quando se avaliou a fundo o tratamento de efluentes regionalmente, se constatou que no período de 2009 a 2013, apenas seis capitais obtiveram índice acima de $80 \%$ de coleta de esgoto, destacando-se positivamente Belo Horizonte com 100\% e Curitiba com 99,07\%, e negativamente capitais da região norte como Manaus, Belém, Porto Velho e Macapá com os piores índices (Instituto Trata Brasil, 2015).

Ao avaliar o tratamento do esgoto que foi coletado, apenas Curitiba se destaca, tratando aproximadamente $88,44 \%$, no entanto o Brasil possui mais de dezenove capitais com níveis de tratamento abaixo de 50\%, mostrando que a cada dez litros de esgoto produzido menos de cinco litros são tratados corretamente (Instituto Trata Brasil, 2015). Trazendo essa análise a nível municipal, apenas $28,5 \%$ dos municípios brasileiros tem tratamento de esgoto e o volume tratado representava em 2008, $68,8 \%$ sob o que era coletado. Apesar de constatado uma melhora nos últimos anos referente ao saneamento básico, um em cada quatro domicílios ainda não tem rede de esgoto (Instituto Brasileiro de Geografia e Estatística, 2009).

Quando pesquisou-se sobre áreas rurais, constatou-se um aumento em relação ao número de pessoas beneficiadas com o abastecimento de água, entretanto cerca de $75 \%$ da população não utilizava nenhum tipo de tratamento de esgoto (IBGE, 2009). Deve-se considerar que a maioria da população encontra-se em extrema pobreza, com pouco ou nenhum acesso a informações relacionadas à educação ambiental, tornando ainda mais difícil a disseminação dos impactos gerados e modelos alternativos de tratamento (Vettore \& Lamarca, 2010).

Baseado nestas informações destaca-se a importância do saneamento básico em áreas rurais, pois a falta do mesmo interfere diretamente na saúde da população e na preservação do meio ambiente (Costa \& Gilhoto, 2008). Entre os impactos gerados resultantes do despejo incorreto do esgoto, pode-se citar a eutrofização, desiquilíbrios ecológicos, assoreamento de solo, contaminação do lençol freático, solo e rios, e proliferação de doenças causadas pelo contato com os dejetos ou com água contaminada (Cavalcante, 2014).

Este problema também impacta na alimentação da população, pois grande parte do que se consome nestas áreas é cultivado pela população local, ou seja, se há contaminação nos solos e água, os alimentos cultivados e consumidos podem estar contaminados (Costa e Gilhoto, 2008).

Para minimizar estes impactos nas áreas rurais, há opções como tratamento de esgoto de raízes e compostagem, fossas sépticas e fossas sépticas biodigestoras (Mielbratz \& Dolzan, 2016).

Considerando o contexto evidenciado, este relato visa apresentar o modelo de fossa biodigestora e os principais pontos de atenção da instalação deste tipo de fossa em zonas rurais, por meio de dois projetos executados em Pedro de Toledo.

Para apresentar as análises e resultados deste estudo, o relato foi estruturado nessa breve introdução, no referencial teórico apresentado à seguir, assim como a metodologia, os resultados obtidos e as conclusões.

\section{REFERENCIAL TEÓRICO}

A OMS (2010) define saneamento como o controle de todos os fatores do meio físico do homem, que exercem ou podem exercer efeitos nocivos sobre o bem estar físico, mental e social.

Os impactos da ausência de saneamento preocupam o mundo, em 2010 a UNICEF divulgou uma lista com os mais graves problemas mundiais, estabelecendo os oito objetivos do desenvolvimento do milênio. Sendo que o sétimo deles refere-se à qualidade de vida e respeito ao meio ambiente, 
mencionado como um dos principais fatores a serem corrigidos à falta de tratamento de esgotos (Embrapa, 2010).

De acordo com o Instituto Trata Brasil (2010) metade da população brasileira não é atendida pela rede pública de coleta de esgoto e 35 milhões de pessoas não possuem banheiros em suas residências. Pesquisas realizadas pela Comissão Econômica para a América Latina (Cepal) inseriram o Brasil em $11^{\circ}$ no ranking latino-americano de saneamento básico, ficando atrás de países como Peru, Bolívia e Venezuela.

Em relação a áreas rurais, apesar de constatado um aumento no número de pessoas atendidas com abastecimento de água, a porcentagem em relação ao tratamento de esgoto, continua estagnado conforme pode ser visualizado no Gráfico 01 (UNICEF, 2010).

Gráfico 01 - Porcentagem de áreas urbanas e rurais sem tratamento de água e esgoto no Brasil.

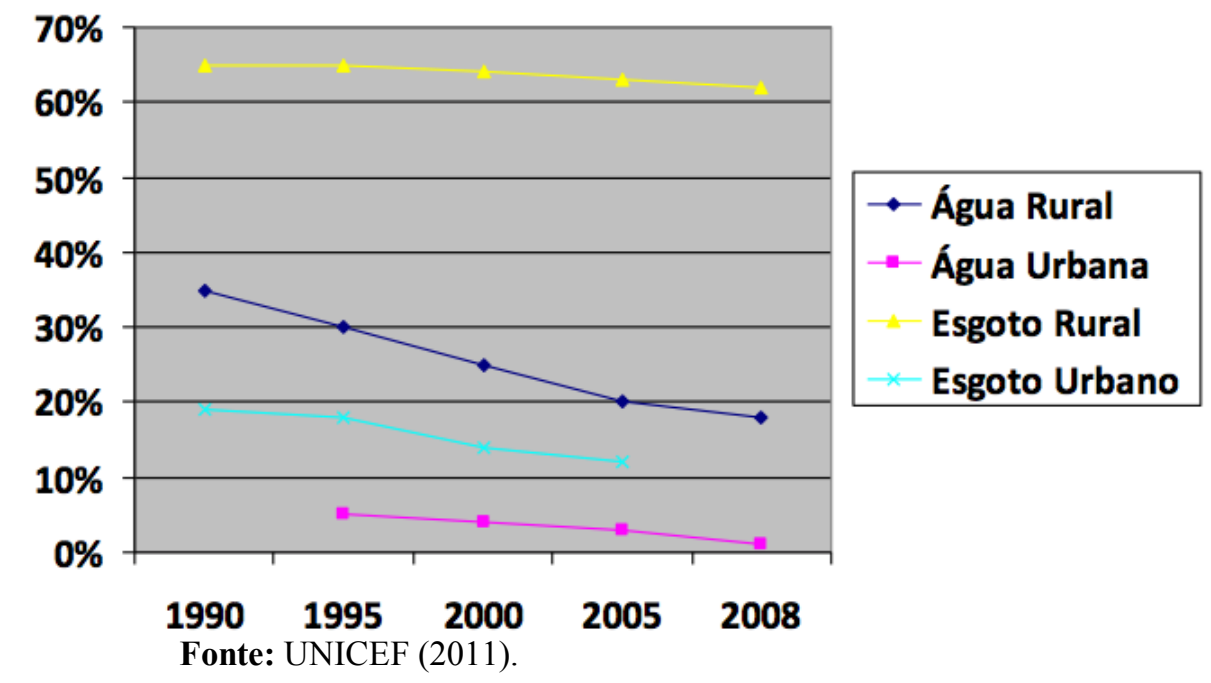

É importante ressaltar que grande parte da população rural encontra-se em condições de extrema pobreza, a dificuldade de acesso a informações e a falta de educação ambiental contribuem para que estas pessoas desconheçam os impactos que o esgoto residual não tratado pode causar no âmbito social e ambiental (Vettore \& Lamarca, 2010).

$\mathrm{Na}$ dimensão social, destacam-se as doenças que podem ser causadas por meio do contato hídrico ou direto com os resíduos como a hepatite, cólera, salmonelose e outras doenças que podem provocar fortes diarreias e levar a óbito (Costa \& Guilhoto, 2014).

No mundo, são diagnosticados por ano aproximadamente 1,7 bilhões de casos de doenças recorrentes da diarreia e cerca de $90 \%$ das mortes causadas pela doença são decorrentes da falta de tratamento de esgoto, destaca-se que anualmente cerca de 04 milhões de crianças morrem (Cavalcante, 2014).

De acordo com dados do Sistema Nacional de Informações Sobre Saneamento (SNIS, 2009) o Brasil registrou em 2009 mais de 462 mil internações por infecção gastrointestinal como diarreia, amebíase e cólera e grande parte destes registros é relacionada a crianças e jovens de até quatorze anos de idade residentes de áreas rurais e regiões do Norte e Nordeste.

Segundo a OMS (2009), o Brasil ocupa a $82^{\circ}$ colocação no ranking de países com maiores números de mortes causados pela diarreia, estima-se que em 1990 cerca de $9 \%$ dos óbitos eram decorrentes a diarreia, em 2000 esta porcentagem diminuiu para $3 \%$ entretanto o resultado ainda é muito alto principalmente se comparado com outros países da América do Sul, como Bolívia $\left(50^{\circ}\right)$ e Guiana $\left(78^{\circ}\right)$.

$\mathrm{Na}$ dimensão ambiental, destaca-se a contaminação do lençol freático, águas subterrâneas, do solo, assoreamento, eutrofização (excesso de nitrato), desequilíbrios 
ecológicos e contaminação dos alimentos produzidos e consumidos na região (Mielbratz \& Dolzan, 2016). Ressalta-se que a eutrofização favorece o surgimento de algas que consequentemente reduz o acesso de luz na água, e em grandes quantidades reduzem drasticamente o oxigênio, alterando o meio aquático e resultando na morte de diversos animais (Embrapa, 2010).

Quando pesquisado sobre métodos de tratamento em áreas rurais, constatou-se que cerca de $48 \%$ da população utiliza fossas rudimentares, principalmente dos modelos, sumidouro e seca. O sumidouro geralmente é construído com anéis pré-moldados de concreto e basicamente é uma técnica de armazenagem direta no solo, pois não há laje de fundo (Silva, Morejon \& Less, 2014).

A fossa seca pode ser encontrada em regiões mais pobres do Brasil, consiste em um buraco escavado no solo, geralmente construído em concreto armado, agregado ou não com um assento (Silva, Morejon \& Less, 2014).

Esses modelos ultrapassados não são ambientalmente corretos, pois os dejetos são somente depositados no solo, provocando a contaminação, pois não existe nenhum tipo de tratamento. Para solucionar este problema nos últimos anos surgiram diversas técnicas de saneamento residencial e rural, que visam tratar o esgoto em pequena escala e com menor tempo, entre elas a fossa séptica e a fossa séptica biodigestora (Leonetti, Prado \& Oliveira, 2010).

A fossa séptica é um sistema primário de tratamento de esgoto que consiste em um tanque enterrado no solo, o sistema retém partes sólidas e realiza um processo biológico de purificação do efluente sanitário e os sólidos devem ser retirados por um caminhão e encaminhados para áreas de tratamento. $\mathrm{O}$ modelo de tratamento diminui o lançamento direto do efluente em rios e diminui cerca de $40 \%$ da demanda biológica de oxigênio (DBO), entretanto durante o processo, há odor desagradável e possível proliferação de vetores (Resende, 2002).

Apesar deste tipo de tratamento amenizar o problema o processo deve ser executado corretamente, pois há possibilidade destes resíduos conterem a presença de organismos patogênicos. Estes microrganismos são capazes de produzir doenças infecciosas e compostos tóxicos, portanto o armazenamento destes pode causar impactos ambientais e sociais (Barros, 2011).

O método utilizado no sistema de fossa séptica biodigestora, recomendado pela Fundação Banco do Brasil para melhorar a qualidade de vida nas áreas rurais, pode ser definido como um processo de biodigestão anaeróbico, em que para se eliminar micróbios e bactérias dos dejetos expelidos pelo ser humano, utiliza-se esterco bovino ou outros mamíferos herbívoros, pode-se citar como exemplos, cabras e ovelhas (Embrapa, 2010).

Destaca-se como principais benefícios: (1) Todo o efluente inserido no sistema é tratado, portanto não há nenhum tipo de contaminação do solo ou pluvial; (2) é possível utilizar o efluente do último processo para fertilização de plantas e hortaliças; (3) possui fácil manuseio; (4) há produção de adubo; e (5) não tem necessidade de retirar os dejetos, no entanto deve-se atentar-se as orientações sugeridas para implantação. O sistema é evidenciado na Figura 1. 


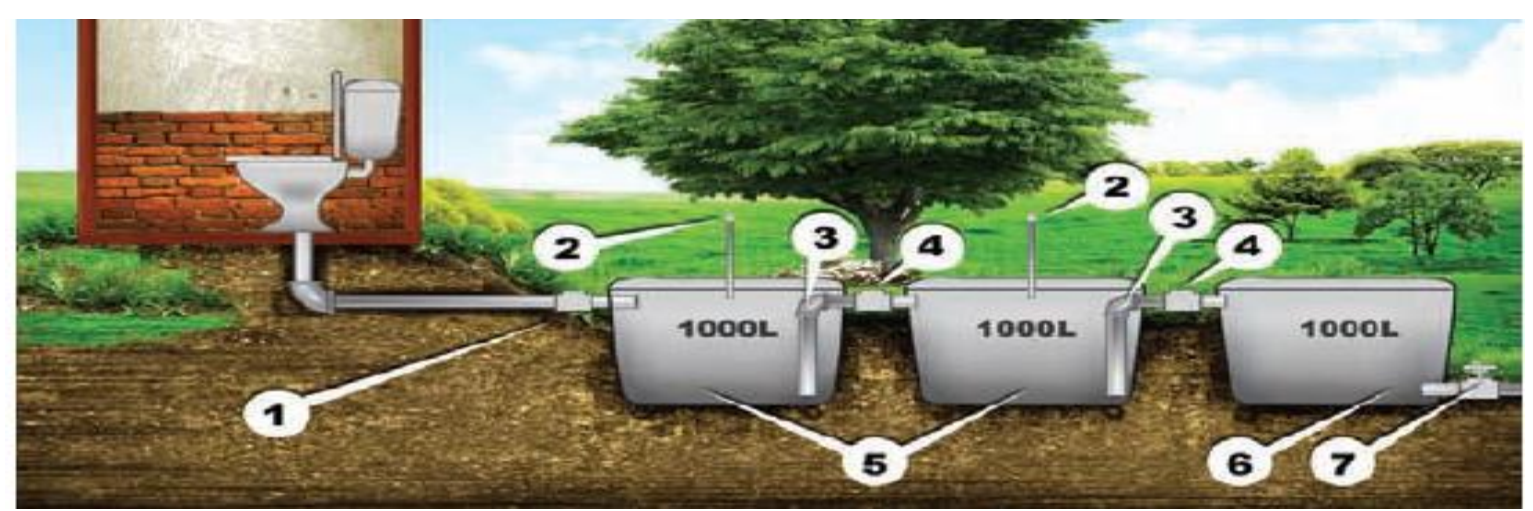

Legenda: (1) Válvula de retenção; (2) Chaminé de Alívio; (3) Curva de 90; (4) “T” de inspeção; (5e 6) Caixas de 1000 litros; e (7) registro.

Figura 1: Projeto de Fossa Biodigestora, modelo Embrapa.

Fonte: Embrapa (2010).

O usuário do sistema pode optar por não utilizar o biofertilizante neste caso deve ser implantado mais uma caixa para realizar a filtração e tornar a água própria para descarte, conforme apresentado na Figura 2. Este sistema de filtragem utiliza materiais simples, encontrados em qualquer casa de construção, como pedra britada, areia lavada e tela de nylon de mosqueteiro.

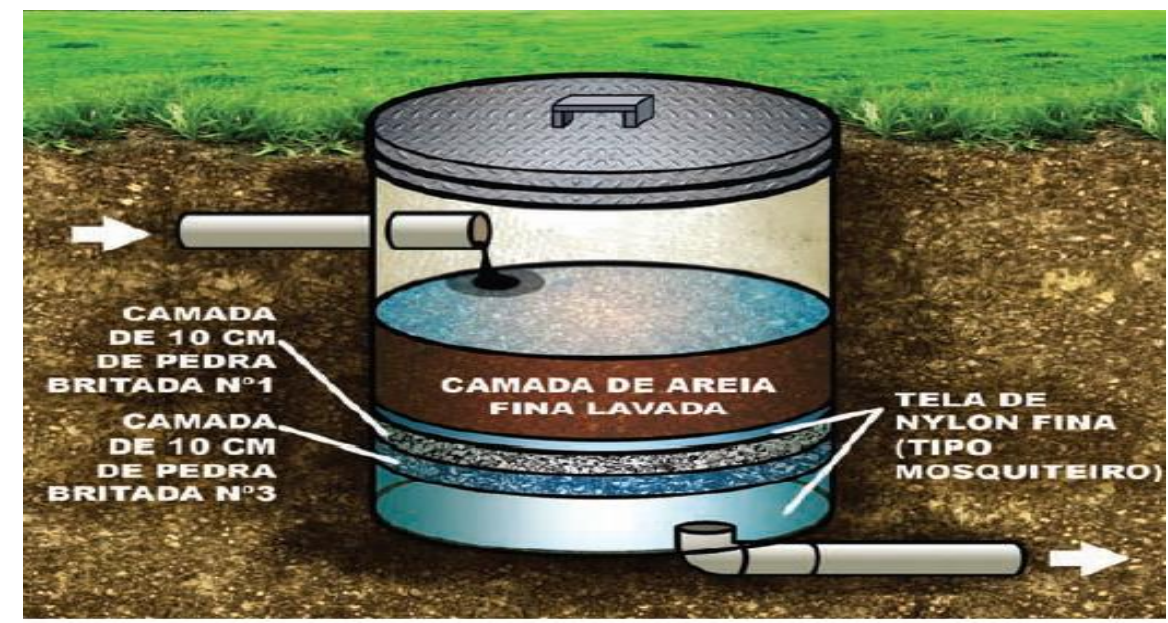

Figura 2: Caixa para filtragem da água, modelo Embrapa.

Fonte: Novaes (2001).

\section{METODOLOGIA}

Utilizando o método de pesquisa-ação conforme sugerido por Martins e Theóphilo (2009), realizou-se o diagnóstico do problema por meio de visitas no decorrer do ano de 2016 e constataram que nos arredores da cidade, principalmente nas moradias mais antigas e distantes do centro da cidade, uma parte da população utilizava fossas rudimentares e outra parte descartava seus dejetos diretamente nos rios. Ambos os processos contaminam o lençol freático, as águas subterrâneas, e o solo (Bettiol \& Antonio de Camargo, 2017). (2010).

A instalação dos projetos foi realizada com base no modelo de fossa biodigestora da Embrapa 


\section{RESULTADOS OBTIDOS}

Os projetos foram implantados em duas propriedades rurais localizadas na cidade de Pedro de Toledo, SP. A cidade faz parte do Parque Estadual da Serra do Mar, considerada uma área de preservação ambiental continua, e tem cerca de 10.000 mil habitantes (IBGE, 2010).

A empresa responsável pelo tratamento de esgoto da região é a Companhia de Saneamento Básico do Estado de São Paulo (SABESP), que atual no centro da cidade e nos bairros Martim Afonso e Manoel da Nóbrega, entretanto Souza, Ferreira, Magini e Abessa (2006) relataram que não há tratamento de esgoto na região de Pedro de Toledo gerando um conflito de informações.

Diante deste conflito, optou-se por realizar visitas na região com o objetivo de confirmar informações, e constatou-se que uma parte da população que não reside no centro da cidade, não tem acesso a tratamento de esgoto e um pequeno grupo de pessoas utiliza fossas rudimentares.

Para implantação do sistema da fossa biodigestora realizou-se os seguintes processos: (1) uma palestra com os proprietários e seus familiares com o intuito de ensinar a utilizar a fossa de maneira correta e mostrar os benefícios do sistema; (2) definiu-se o local ideal para implantação, levando em consideração que o mesmo deveria ficar próximo a casa, um pouco abaixo do nível do sanitário e o mais distante possível dos cursos d'agua; (3) após a definição do local, realizou-se a escavação para instalação das caixas d'agua; (4) inserção das caixas em seus lugares e realização dos cortes necessários para introdução dos tubos; (5) introdução dos tubos e vedação das caixas utilizando $50 \mathrm{~cm}$ de desnível entre a primeira caixa e a última caixa; e (6) introdução de areia, pedra e manta na última caixa.

\section{Projeto 01}

A primeira fossa foi instalada em uma propriedade afastada do centro da cidade e dos bairros. Nesta propriedade, o descarte dos efluentes era realizado diretamente para um rio próximo, sem nenhum processo de tratamento. Para esse sistema, foram realizadas algumas adaptações do projeto da Embrapa (2010): utilizaram-se caixas de polietileno e reforçou-se a vedação das caixas com borracha. A instalação da fossa é evidenciada na Figura 3.

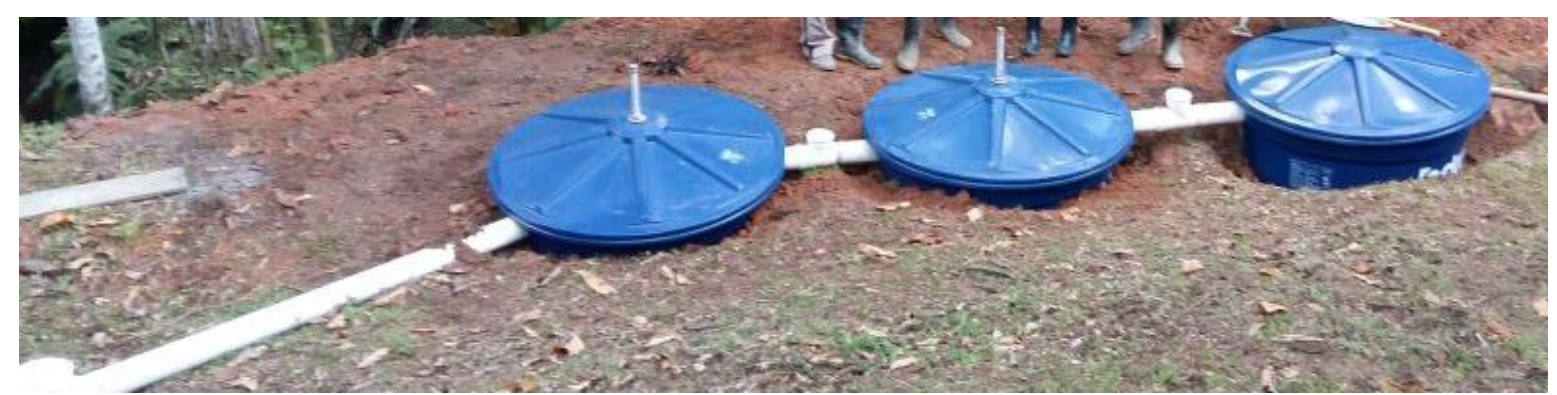

Figura 3: Projeto de fossa biodigestora na propriedade 01, executado em Março de 2017.

Fonte: Os autores.

As escavações dos buracos para inserção das caixas e as conexões diretas com os sanitários foram às etapas mais demoradas e braçais do processo de instalação. Neste projeto, as escavações ocorreram antes da chegada dos materiais, acarretando em um problema na instalação, pois os buracos ficaram maiores do que as caixas compradas. Para a correção, as escavações foram preenchidas novamente com o solo retirado e niveladas com as caixas. 
Uma visita de inspeção foi realizada uma semana após a instalação. Nesta visita, foi identificado que, em função de chuvas torrenciais e do problema que ocorreu na instalação, um pouco da terra abaixo da primeira caixa foi levada pela chuva e fez com que a mesma se desnivelasse, tornando necessária uma nova correção. Foi necessária a retirada da caixa desnivelada, a correção do buraco e uma nova instalação.

Também foi identificado um vazamento no vaso sanitário que encheu de água todo o sistema. O vazamento foi consertado e as caixas esvaziadas, como o sistema ainda não tinha sido utilizado, a água foi descartada sem problemas de contaminação.

Após esses ajustes na instalação, o projeto foi finalizado e iniciado o uso do sistema pelos frequentadores do local.

\section{Projeto 02}

A segunda fossa foi instalada em uma propriedade situada em um bairro afastado da cidade. No local existia uma fossa rudimentar, método muito utilizado na região. Para esse sistema, também foram realizadas algumas adaptações do projeto da Embrapa (2010): utilizaram-se caixas de polietileno e reforçou-se a vedação das caixas com borracha. A instalação da fossa é evidenciada na Figura 4.

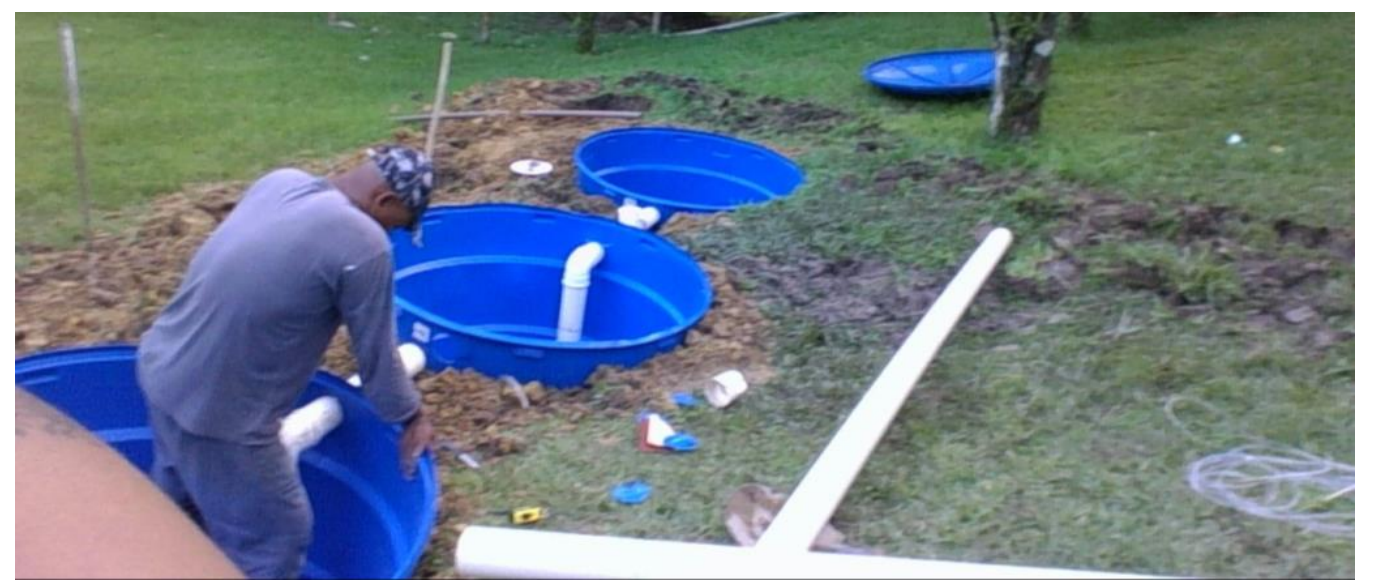

Figura 4: Projeto de fossa biodigestora na propriedade 02, executado em Abril de 2017. Fonte: Os autores.

Para não se ter o problema na instalação das caixas, optou-se por iniciar as escavações após a compra dos materiais, assim o buracos foram sendo ajustados com as próprias caixas. Esse processo reduziu o esforço da instalação em um dia. Para evitar que as caixas se desnivelassem em função das chuvas, após a instalação e antes da inserção das tampas das caixas, se preencheu cada caixa com 30 centímetros de água. Essa ação visou deixar as caixas mais pesadas e aderentes aos buracos.

$\mathrm{Na}$ instalação deste projeto não ocorreu problemas, entretanto, se constatou que o sistema de esgoto da propriedade não separava a água dos chuveiros e lavatórios do esgoto, o que levou à equipe planejar essa separação após a instalação da fossa. Em uma segunda etapa do projeto, a água do esgoto foi separada.

Conforme dito anteriormente este sistema é indicado para conexões diretas com o vaso sanitário, pois devido a grande quantidade de água proveniente de pias e chuveiros, as caixas podem ficar cheias de água impactando no processo biológico dos dejetos e tornando o processo ineficiente.

Ambos os projetos foram realizados durante o primeiro semestre de 2017, a seguir relata-se as conclusões sobre a implantação dos projetos e as lições aprendidas. 


\section{CONCLUSÕES E CONSIDERAÇÕES FINAIS.}

As escavações dos buracos para inserção das caixas e as conexões diretas com os sanitários foram às etapas mais demoradas e braçais do processo de instalação, levando em média três dias para execução. A implantação de ambos os projetos ocorreu em cinco dias com um grupo de quatro pessoas.

Caso a água dos lavatórios e chuveiros estiverem unidas com o esgoto, é necessária a separação desse sistema para que a fossa biodigestora funcione corretamente. Caso essa divisão não for possível, durante a utilização deve-se atentar para a quantidade de produtos químicos utilizados na limpeza dos sanitários e inserir mais esterco na fossa biodigestora.

Alguns dos materiais para a construção das fossas biodigestoras não foram encontrados nas casas de construção da cidade de Pedro de Toledo, como a válvula de retenção. Recomenda-se a pesquisa para a compra dos materiais em mais de um local ou cidade, quando a mesma for pequena.

A Embrapa (2010) recomenda que o material das caixas utilizadas seja fibra de vidro, fibrocimento ou manilha de concreto, não sendo recomendável a utilização de caixas de polietileno, pois esse material não permite o emprego de cola de silicone para a vedação, entretanto, como não foi encontradas caixas de fibra de vidro na região na qual foi desenvolvido os projetos e as caixas de fibrocimento ou manilha inviabilizavam o projeto em função do custo elevado dos materiais e problemas logísticos, adaptou-se a forma de vedação utilizando borracha de pneus na vedação das tampas de caixas de polietileno.

Espera-se que o projeto reduza a quantidade de mortes causadas por diarreia continua, doenças diarreicas, a demanda bioquímica de oxigênio, as altas cargas de nutrientes (fósforo e nitrato) lançados no solo e nas águas, e que diminua o uso de fertilizante químico.

Pode-se citar como contribuição social deste relato, a divulgação dos problemas e possíveis soluções da instalação de fossas biodigestoras em áreas rurais. Essa divulgação permite que outros pesquisadores e proprietários de áreas rurais, adotem as soluções e contornos descritos neste relato.

Como contribuição ambiental, pode-se citar a propagação de informações sobre a importância de preservar o meio em que vivemos por meio da implantação de fossas biodigestoras e diminuição de dejetos descartados incorretamente, além de propiciar aos moradores da região uma interação real com a sustentabilidade.

\section{REFERÊNCIAS}

Barros H. L. (2011), Biodiversidade em questão, Rio de Janeiro: Claro Enigma/Fiocruz. Bettiol, W., \& Antonio de Camargo, O. (2006). Lodo de esgoto: Impactos ambientais na agricultura. Empresa Brasileira De Agropecuária.

Cavalcante, R. (2014). Ocorrência de Escherichia coli em fontes de água e pontos de consumo em uma comunidade rural. Ambiente e Água - An Interdisciplinary Journal Of Applied Science, 9(3). http://dx.doi.org/10.4136/ambi-agua.1301.

Costa, C. C., \& Guilhoto, J. J. M. (2014). Saneamento rural no Brasil: impacto da fossa séptica biodigestora. Engenharia Sanitaria E Ambiental, 19(spe), 51-60. https://doi.org/10.1590/S1413-41522014019010000171.

Embrapa (2010). Tecnologia social, fossa séptica biodigestora: Saúde e renda no campo. Brasília: Fundação Banco do Brasil.

IBGE (2009). Atlas de Saneamento 2011 Acesso em: 22 de Jun. de 2017. Disponível em: http://www.ibge.gov.br/home/estatistica/populacao/atlas_saneamento/default_zip.shtm.

Instituto Trata Brasil - Ranking do Saneamento (2015). Acesso em: 22 Jun. de $201 \overline{7}$. Disponível em: http://www.tratabrasil.org.br/ranking-do-saneamento-2015. 
Instituto Trata Brasil. (2017). Vergonha: Metade da população brasileira não tem coleta de esgoto. Acesso em: 22 Jun. 2017, Disponível em:

http://www.tratabrasil.org.br/vergonha-1-metade-da-populacao-brasileira-nao-temcoleta-de-esgoto.

Martins, G. A., \& Theóphilo, C. R. (2009). Metodologia da investigação científica para ciências sociais aplicadas. São Paulo: Atlas.

Mielbratz, M., \& Dolzan, M. V. (2016). O tratamento de esgotos e dejetos em propriedades rurais sustentáveis. Maiêutica-Gestão Ambiental, 4(1), 75-82.

Resende, A. V. (2002). Agricultura e qualidade de água: contaminação por nitrato. Planaltina: Embrapa Cerrados.

SNIS - Sistema Nacional de Informações Sobre Saneamento (2015) Diagnóstico água e Esgoto. . Acesso em: 20 de Jun. de 2017. Disponível em http://www.snis.gov.br/diagnostico-agua-e-esgotos/diagnostico-ae-2015.

Silva D. F., Morejon C. F. M., Less R. F., (2014) Prospecção do panorama do saneamento rural e urbano no Brasil. Revista Eletrônica do Mestrado em Educação Ambiental. Universidade Federal do Rio Grande - FURG.

Sousa I. F.; Ferreira L. E. C., Magini Christiano, Abessa D. M. S. (2006). Percepção ambiental, perfil sócio-econômico e uso e ocupação do solo pela comunidade residente no núcleo Pedro de Toledo - Parque Estadual da Serra do Mar - SP. Scamilo.Edu.Br, 30(4), 570-580.

Leoneti, A., Prado, E., \& Oliveira, S. (2010). Saneamento básico no Brasil: considerações sobre investimentos e sustentabilidade para o século XXI. Revista De Administração Pública. Acesso em: 22 de Jun. de 2017 Disponível em: http://producao.usp.br/handle/BDPI/6136.

UNICEF/OMS (2009) Diarrhoea: why children are still dying and what can be done. Genebra: World Health Organization. Acesso em: 22 de Jun. de 2017. Disponível em: http://apps.who.int/iris/bitstream/10665/44174/1/9789241598415_eng.pdf.

UNICEF/OMS (2010) Progress on sanitation and drinking-water. France: World Health Organization. Acesso em: 22 de Jun. de 2017. Disponível em: https:/www.wssinfo.org/fileadmin/user_upload/resources/1278061137JMP_report_2010_en.pdf.

UNICEF (2011). Health statistics. Acesso em 21 de Jun. de 2017. Disponível em: https://www.unicef.org/sowc09/statistics/tables.php

Vettore M, Lamarca G., Censo 2010: Uma leitura dos resultados sobre saneamento básico. Rio de Janeiro: Portal DSS Brasil. Acesso em: 22 de Jun. de 2017. Disponível em: http://cmdss2011.org/site/?p=7831\&preview=true. 